\title{
Lung function abnormalities in patients infected with the human immunodeficiency virus with and without overt pneumonitis
}

\author{
R J SHAW, C ROUSSAK, S M FORSTER, J R W HARRIS, A J PINCHING, \\ D M MITCHELL
}

From St Mary's Hospital, London

ABSTRACT Pulmonary function was measured in 169 male patients seropositive for the human immunodeficiency virus (HIV). The transfer factor for carbon monoxide (TLCO) in symptom free patients and patients with persistent generalised lymphadenopathy was normal ( $>83 \%$ of predicted values). Patients with the AIDS related complex, non-pulmonary Kaposi sarcoma, and nonpulmonary non-Kaposi sarcoma AIDS (that is, opportunist infections affecting other organs) had lower mean values for TLCO $(77 \%, 70 \%$, and $70 \%$ of predicted respectively). These values were significantly lower than values for symptom free patients. Lower mean values of $50 \%$ and $63 \%$ predicted TLCO were observed in patients during the acute and recovery phases of Pneumocystis carinii pneumonia. TLCO was also low in patients with lung mycobacterial infection and in a patient with lung Kaposi sarcoma. Forced expiratory volume in one second, peak expiratory flow, and maximal expiratory flow at $50 \%$ of vital capacity were significantly reduced only in patients with acute pneumocystis pnemonia. This study shows that abnormalities in the results of pulmonary function tests, particularly TLCO, although greatest in patients with pulmonary complications of AIDS, are also present in patients with AIDS but without other evidence of pulmonary disease, and in patients with the AIDS related complex. The predictive and prognostic implications of these findings require further investigation.

Disease produced by the human immunodeficiency virus (HIV) is rapidly becoming a major health care problem. Pulmonary complications occur in over $40 \%$ of patients. $^{12}$ Of these, Pneumocystis carinii pneumonia is the most common $(84 \%)$, and may pose diagnostic difficulties because the symptoms of breathlessness and cough often have an insidious onset and may have other causes. Physical examination is rarely helpful and the chest radiograph may be normal. Low values for carbon monoxide transfer factor (TLCO) and vital capacity (VC) have been shown to occur in acute Pneumocystis carinii infection. ${ }^{36}$ In this study we report abnormalities of pulmonary function in other categories of HIV related disease and compare them with those found in patients with AIDS and pneumocystis pneumonia.

Address for reprint requests: Dr D M Mitchell, Department of Respiratory Medicine, St Mary's Hospital, London W2 INY.

Accepted 26 January 1988

\section{Methods}

We studied 169 male homosexual HIV seropositive patients. They were classified according to clinical features:

1 thirty three were symptom free but HIV seropositive (Centre for Disease Control (CDC) group 요 II $^{7}$;

2 forty seven subjects had persistent generalised lymphadenopathy (CDC group III);

3 thirty three subjects had AIDS related complex (CDC group IV, subgroups A, B, C2, E);

4 sixteen subjects had non-pulmonary Kaposi sarcoma, mainly affecting the skin (CDC group IV, subgroup D);

5 six subjects had non-pulmonary non-Kaposi sarcoma AIDS - that is, opportunist infection affecting other organs (CDC group IV, subgroup C1); 6 thirty four patients had AIDS with pulmonary complications (pulmonary AIDS)-13 with acute 8 pneumocystis pneumonia (CDC group IV, subgroup 
C1), 17 with an episode of pneumocystis pneumonia more than one month previously, three with lung mycobacterial infection, and one with lung Kaposi sarcoma.

Patients seropositive for HIV with an abnormal chest radiograph, a TLCO value less than $60 \%$ predicted, or prominent respiratory symptoms - that is, persistent cough or moderate to severe exertional dyspnoea-underwent fibreoptic bronchoscopy with bronchoalveolar lavage and transbronchial biopsy, ${ }^{8}$ unless they were considered too ill for the procedure to be done with safety or they refused the procedure.

All patients had the following lung function tests: forced expiratory volume in one second $\left(\mathrm{FEV}_{1}\right)$, peak expiratory flow (PEF), maximum expiratory flow at $50 \%$ of vital capacity $\left(\mathrm{MEF}_{50}\right)$, forced vital capacity (FVC), single breath alveolar volume (VA), and carbon monoxide transfer factor or diffusing capacity (TLCO). The transfer coefficient (KCO) was derived from the TLCO and VA. Measurements were made with a dry bellows spirometer and the single breath helium dilution method (P K Morgan transfer test model C machine: P K Morgan, Gillingham, Kent). Corrections for body temperature and haemoglobin concentration ${ }^{9}$ were included in the calculation of TLCO values.

Lung function testing apparatus designated for HIV seropositive patients was used throughout with modifications to reduce the risk of cross infection between patients. One way valve safety mouthpieces (Vitalograph Ltd, Buckingham) were used for spirometry. A Pall Ultipor breathing system filter (Pall Biomedical, Havant, Portsmouth) was placed distal to the mouthpiece during the carbon monoxide transfer test. The increased deadspace of $150 \mathrm{ml}$ due to the presence of the filter was incorporated in the calculation.

Plastic mouthpieces and nose clips were sterilised in $2 \%$ glutaraldehyde for one hour between tests on different patients and the remainder of the apparatus was dismantled and sterilised weekly for at least three hours in $2 \%$ glutaraldehyde. Values were compared with those predicted for age, sex, and height for each patient and expressed as mean percentages of predicted values. ${ }^{9}$ Statistical comparisons were made by means of Student's $t$ tests between symptom free HIV antibody positive patients (disease control) and other groups.

\section{Results}

One hundred and sixty nine patients completed the study. Details of age, smoking history, and dyspnoea are given in table 1. Mild dyspnoea was recorded if the patient complained of breathlessness on stairs or hills and severe dyspnoea if he was breathless on minimal exertion or at rest. TLCO, KCO, and FVC in symptom free HIV positive patients and those with persistent generalised lymphadenopathy were normal, with values greater than $83 \%$ predicted (fig 1). There was no significant difference between the two groups for any of the measurements.

\section{PATIENTS WITH AIDS RELATED COMPLEX AND \\ NON-PULMONARY AIDS}

TLCO and FVC were significantly lower in patients with the AIDS related complex than in the symptom free HIV positive group ( $p<0.05$ and $<0.001)$.

TLCo was low in patients with AIDS who had Kaposi sarcoma (mainly cutaneous) but no pulmonary disease $(p<0.01)$. In patients with AIDS with neither Kaposi sarcoma nor pulmonary disease (that is, with opportunist infections affecting other organs) both TLCO and KCO were lower than in the symptom free HIV positive group ( $<<0.01$ and $<0.05$ ).

\section{PATIENTS WITH AIDS AND PULMONARY COMPLICATIONS}

Patients with AIDS and pulmonary complications had greater reductions in lung function. Mean TLCO, KCO, and FVC were lower in acute pneumocystis pneumonia than in the HIV positive group $(p<0.001$, $<0.01,<0.001)$ or in the patients with non-pulmonary Kaposi sarcoma $(\mathrm{p}<0.001,<0.05,<0.001)$, and TLCo and FVC were lower than in AIDS patients without Kaposi sarcoma or opportunist lung infection

Table 1 Age ranges, smoking habits, and breathlessness of patients in the different groups

\begin{tabular}{|c|c|c|c|c|c|c|c|c|c|}
\hline & $\begin{array}{l}H I V+ \\
(n=33)\end{array}$ & $\begin{array}{l}P G L \\
(n=47)\end{array}$ & $\begin{array}{l}A R C \\
(n=33)\end{array}$ & $\begin{array}{l}\text { Non-lung } \\
K S \\
(n=16)\end{array}$ & $\begin{array}{l}\text { Non-KS } \\
\text { non-lung } \\
\text { AIDS } \\
(n=6)\end{array}$ & $\begin{array}{l}\text { Acute } \\
P C P \\
(n=13)\end{array}$ & $\begin{array}{l}\text { Post } \\
\text { PCP } \\
(n=17)\end{array}$ & $\begin{array}{l}\text { Lung } \\
\text { myco } \\
(n=3)\end{array}$ & $\begin{array}{l}\text { Lung } \\
K S \\
(n=1)\end{array}$ \\
\hline $\begin{array}{l}\text { Age range }(y) \\
\text { Smokers }(\%) \\
\text { Mild dyspnoea }(\%) \\
\text { Severe dyspnoea }(\%)\end{array}$ & $\begin{array}{l}22-49 \\
60 \\
3 \\
0\end{array}$ & $\begin{array}{l}23-49 \\
87 \\
17 \\
0\end{array}$ & $\begin{array}{l}19-50 \\
69 \\
39 \\
3\end{array}$ & $\begin{array}{l}23-57 \\
76 \\
41 \\
0\end{array}$ & $\begin{array}{l}26-38 \\
67 \\
33 \\
0\end{array}$ & $\begin{array}{l}26-51 \\
73 \\
73 \\
20\end{array}$ & $\begin{array}{l}24-53 \\
47 \\
35 \\
0\end{array}$ & $\begin{array}{l}37-63 \\
67 \\
100 \\
0\end{array}$ & $\begin{array}{l}42 \\
\text { Smoker } \\
0 \\
0\end{array}$ \\
\hline
\end{tabular}



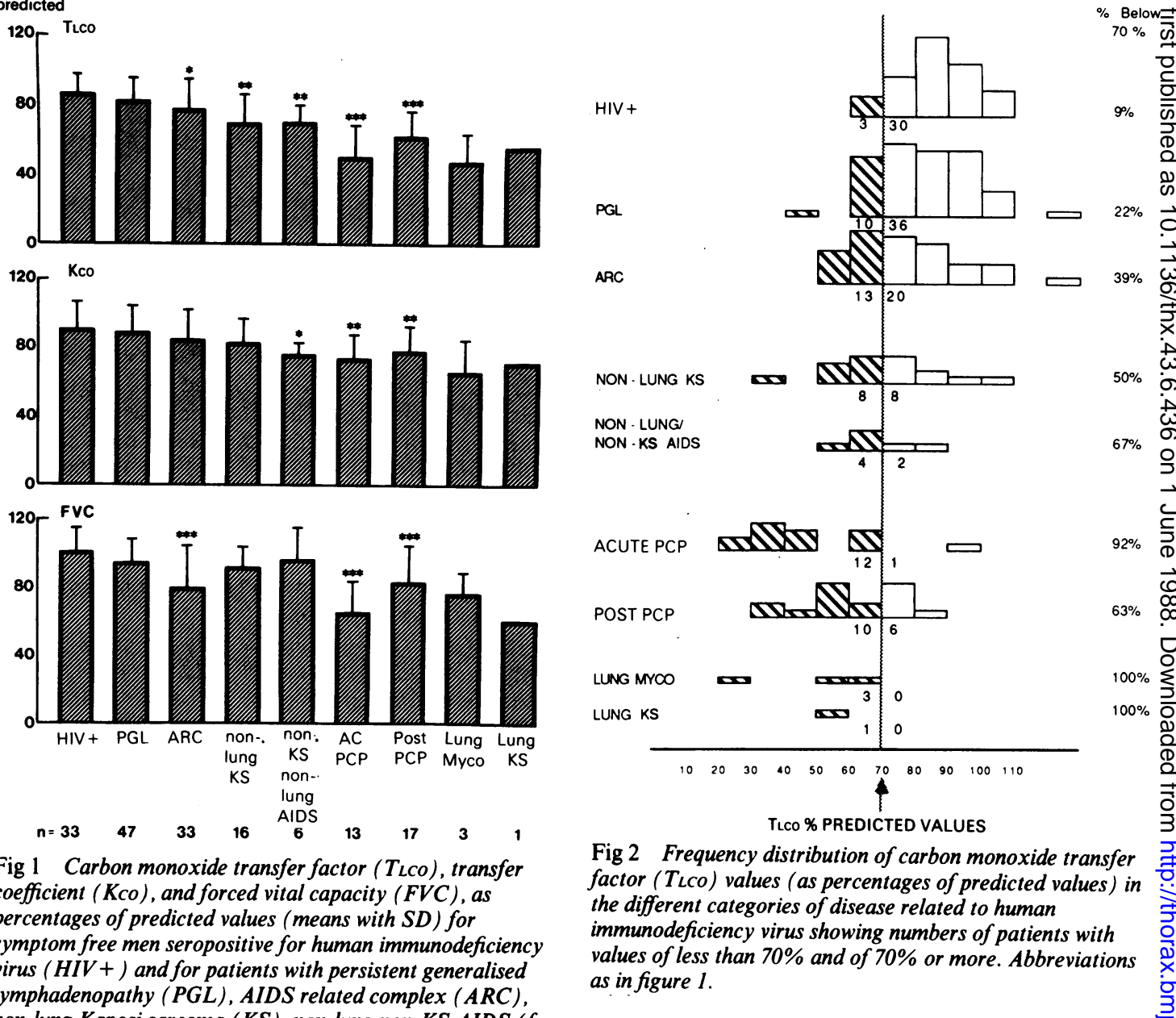

Fig 1 Carbon monoxide transfer factor ( $\left.T_{L C O}\right)$, transfer coefficient (KCo), and forced vital capacity (FVC), as percentages of predicted values (means with $S D$ ) for symptom free men seropositive for human immunodeficiency virus $(\mathrm{HIV}+)$ and for patients with persistent generalised lymphadenopathy (PGL), AIDS related complex (ARC), non-lung Kaposi sarcoma (KS), non-lung non-KS AIDS (for example, cytomegalovirus infection at non-pulmonary site), acute Pneumocystis carinii pneumonitis (PCP), post PCP (more than one month after episode), atypical mycobacterial lung infection (lung myco) and lung Kaposi sarcoma. ${ }^{*} p<0.05 ;{ }^{* *} p<0.01 ;{ }^{* * *} p<0.001$.

$(\mathrm{p}<0.05,<0.01)$. For patients with acute pneumocystis pneumonia the mean value of TLCo was $50 \%$ (SD 19\%) of predicted. Only one of 13 patients with acute pneumocystis pneumonia had a TLCo value greater than $70 \%$ predicted. Low values for TLCo were also seen in patients with AIDS who had pulmonary mycobacterial infection and in those recovering from 0 acute pneumocystis pneumonia $(p<0.001)$. There were no differences in any of the measurements $\frac{0}{2}$ between patients with acute pneumocystis pneumonia and those with lung mycobacterial infections. In those $\sigma$ who had recovered from acute pneumocystis $N$ pneumonia (post pneumocystis pneumonia) the $\mathrm{N}_{\mathrm{W}}$ measurements did not differ significantly from the Table 2 Indices of lung function (mean percentages of predicted values with SD in parentheses) measured during forcedo expiration

\begin{tabular}{|c|c|c|c|c|c|c|c|c|c|}
\hline & $\begin{array}{l}H I V+ \\
(n=33)\end{array}$ & $\begin{array}{l}P G L \\
(n=47)\end{array}$ & $\begin{array}{l}A R C \\
(n=33)\end{array}$ & $\begin{array}{l}\text { Non-lung } \\
K S \\
(n=16)\end{array}$ & $\begin{array}{l}\text { Non-KS } \\
\text { non-lung } \\
\text { AIDS } \\
(n=6)\end{array}$ & $\begin{array}{l}\text { Acute } \\
P C P \\
(n=13)\end{array}$ & $\begin{array}{l}\text { Post } \\
P C P \\
(n=17)\end{array}$ & $\begin{array}{l}\text { Lung } \\
\text { myco } \\
(n=3)\end{array}$ & $\begin{array}{l}\text { Lung } \\
K S=1) \\
(n=1)\end{array}$ \\
\hline $\begin{array}{l}\text { FEV } \\
\text { PEF } \\
\text { MEF }_{50}\end{array}$ & $\begin{array}{l}109(17) \\
95(16) \\
94(29)\end{array}$ & $\begin{array}{r}100(20) \\
92(16) \\
86(24)\end{array}$ & $\begin{array}{l}93(21) \\
85(19) \\
88(29)\end{array}$ & $\begin{array}{l}103(13) \\
98(26) \\
93(19)\end{array}$ & $\begin{array}{l}96(21) \\
90(26) \\
85(24)\end{array}$ & $\begin{array}{l}73(19) \\
71(15) \\
76(23)\end{array}$ & $\begin{array}{l}95(21) \\
86(20) \\
87(26)\end{array}$ & $\begin{array}{l}95(16) \\
71(15) \\
77(21)\end{array}$ & $\begin{array}{l}65 \\
37 \\
52\end{array}$ \\
\hline
\end{tabular}


values in the other non-pulmonary AIDS groups. The patient with pulmonary Kaposi sarcoma had TLCO, $\mathrm{KCO}$, and FVC values of $56 \%, 70 \%$, and $60 \%$.

Although there were significant differences between mean values for TLCo between patients with AIDS and pulmonary disease and other HIV positive patients, there was some overlap (fig 2 ). If a TLCo value of less than $70 \%$ predicted were used to diagnose pneumocystis pneumonia the sensitivity of the test would be $92 \%$ and the specificity $72 \%$. The positive predictive value would be only $24 \%$, whereas the negative predictive value would be $99 \%$.

Measurements of airway function $\left(\mathrm{FEV}_{1}, \mathrm{PEF}\right.$, $\mathrm{MEF}_{50}$ ) gave values within the normal predicted range in the HIV positive, persistent generalised lymphadenopathy, AIDS related complex, and non-pulmonary AIDS groups (table 2). Patients with pulmonary complications of AIDS (acute pneumocystis pneumonia, post pneumocystis pneumonia, lung Kaposi sarcoma, and lung mycobacterial infection) had reductions in FEV, $\mathrm{PEF}$, and $\mathrm{MEF}_{50} . \mathrm{FEV}_{1}$ and PEF were significantly lower $(p<0.01)$ in acute pneumocystis pneumonia than in the symptom free HIV positive group.

\section{Discussion}

Like previous studies, this investigation showed that a low value for TLCO was a sensitive index of pulmonary disease in AIDS, ${ }^{6}$ being reduced in over $90 \%$ of patients with acute pneumocystis pneumonia ( 12 of 13 patients). Low values for TLCO were not specific for acute pneumocystis pneumonia, similar reductions being seen in the other pulmonary complications of AIDS (recovery from pneumocystis pneumonia, lung Kaposi sarcoma, and mycobacterial infection). None of the patients in this study practised intravenous drug abuse, which is independently associated with a low TLCO value. ${ }^{10}$ The interesting observation of this study was that TLCo was significantly lower in patients with AIDS who had no clinical evidence of pulmonary complications and in patients with the AIDS related complex than in symptom free HIV positive patients or those with persistent generalised lymphadenopathy. Furthermore, a significant reduction in FVC was seen in patients with the AIDS related complex. The proportion of patients with dyspnoea on exertion was also greater in the AIDS related complex and nonpulmonary Kaposi sarcoma than in symptom free HIV positive patients and those with persistent generalised lymphadenopathy (table 1). Similar numbers were smokers in all the HIV disease categories.

There are several possible explanations for these findings. Pneumocystis pneumonia can have an insidious onset lasting up to three months. " 12 Possibly some of those with non-pulmonary AIDS in fact had "early" pneumocystis pneumonia and abnormalities of lung function were the first manifestation. Similarly, the abnormalities seen in patients with the AIDS related complex may be the first indication of the slow development of their first opportunist pulmonary infection or neoplasm. Alternatively, infection with HIV may result in lung damage directly. Direct damage occurs in other organs (for example, in AIDS encephalopathy ${ }^{13}$ ), and HIV has been isolated from lung tissue and alveolar macrophages from patients with AIDS. ${ }^{14}$ The changes in pulmonary function may therefore be the result of a non-specific interstitial pneumonitis, which is being increasingly recognised in the context of HIV related disease. ${ }^{1516}$ Prospective longitudinal studies may clarify this issue. We did not routinely measure arterial blood gas tensions or the alveolar-arterial oxygen difference in these patients (although arterial blood gas tensions were measured before bronchoscopy).

This study showed that routine lung function tests, particularly the TLCO, were a useful adjunct in identifying patients with pulmonary complications of AIDS, the values being lower than in the other patients who had reductions. In view of the overlap with other groups of patients, however, abnormalities of lung function need to be interpreted and acted on in the context of the clinical presentation and the chest radiograph. Isolated measurements are probably of less value than sequential measurements. A reduction in TLCO is, however, a sensitive if not specific index of pulmonary complications in AIDS, and if found in an individual patient should encourage further investigation, such as bronchoscopy. This study also showed that abnormalities in results of lung function tests occurred without overt clinical evidence of pulmonary disease in patients with HIV infection. A satisfactory explanation for the observed reductions in lung function in those with the AIDS related complex and nonpulmonary AIDS remains to be found, and the prognostic and predictive value of these changes needs to be evaluated.

This study was supported by the British Lung Foundation.

\section{References}

I Murray JF, Felton CP, Garrays SM, et al. Pulmonary complications of the acquired immunodeficiency syndrome: Report of a National Heart, Lung and Blood Institute Workshop. N Engl J Med 1984;310:1682-8.

2 Center for Disease Control. Update: acquired immunodeficiency syndrome (AIDS)-United States. Morbidity and Mortality Weekly Report 1985;34:245-8.

3 Coleman DL, Dodek PM, Golden JA, et al. Correlation between serial pulmonary function tests and fibreoptic bronchoscopy in patients with Pneumocystis carinii 
pneumonia and the acquired immune deficiency syndrome. Am Rev Respir Dis 1984;129:491-3.

4 Hopewell PC, Luce JM. Pulmonary involvement in the acquired immunodeficiency syndrome. Chest 1985; 87:104-12.

5 Stover DE, White DA, Romano PA, Gellene RA, Robeson WA. Spectrum of pulmonary disease associated with the acquired immunodeficiency syndrome. Am J Med 1985;78:429-37.

6 Curtis J, Goodman P, Hopewell PC. Noninvasive tests in the diagnostic evaluation for $\boldsymbol{P}$ carinii pneumonia in patients with or suspected of having AIDS [abstract]. Am Rev Respir Dis 1986;133:A182.

7 Center for Disease Control. Classification system for HIV infections. Morbidity and Mortality Weekly Report 1986;35:334-9.

8 Warren JB, Shaw RJ, Weber JN, Holt DA, Keal EE, Pinching AJ. Role of fibreoptic bronchoscopy in management of pneumonia in acquired immune deficiency syndrome. Br Med J 1985;291:1012-3.

9 Cotes JE. Lung function: assessment and application in medicine. 4th ed. Oxford: Blackwell Scientific Publications, 1979.

10 Overland ES, Nolan AJ, Hopewell PC. Alteration of pulmonary function in intravenous drug abusers: prevalence severity and characterisation of gas exchange abnormalities. Am J Med 1980;68:231-7.

11 Engelberg LA, Lerner CE, Tapper ML. Clinical features of Pneumocystis pneumonia in the acquired immune deficiency syndrome. Am Rev Respir Dis 1984;130: 689-94.

12 Kovacs JA, Kremenz JW, Macher AM, et al. Pneumocystis carinii pneumonia: a comparison between patients $\omega$ with the acquired immunodeficiency syndrome and $\vec{\circ}$ patients with other inmunodeficiencies. Ann Intern Med 1984;100:663-71.

13 Epstein LG, Sharer LR, Cho E-S, et al. HTLVIII/LAVlike retrovirus particles in the brains of patients with AIDS encephalopathy. AIDS Research 1985;1:447-54.

14 Salahuddin SZ, Rose RM, Groopman JE, Markham PD, c屯 Gallo RC. Human T lymphotropic virus type III 0 infection of human alveolar macrophages. Blood 1986;68:281-4.

15 Suffredini AF, Ognibene FP, Lack EE, et al. Non-specific 을 interstitial pneumonitis: a common cause of pulmonary $\overrightarrow{ }$ disease in the acquired immunodeficiency syndrome. Ann Intern Med 1987;107:7-13.

16 Murray JF, Garay SM, Hopewell PC, et al. Pulmonary $\vec{\bullet}$ complications of the acquired immunodeficiency syn- $\infty$ drome: an update. Am Rev Respir Dis 1987;135:504-9. 